\title{
Production of scFv, Fab, and IgG of CR3022 Antibodies Against SARS-CoV-2 Using Silkworm-Baculovirus Expression System
}

\author{
Takeru Ebihara ${ }^{1}$ - Akitsu Masuda ${ }^{1} \cdot$ Daisuke Takahashi $^{2} \cdot$ Masato Hino $^{3} \cdot$ Hiroaki Mon ${ }^{4} \cdot K^{\prime}$ Kohei Kakino ${ }^{1}$. \\ Tsuguru Fujii ${ }^{5} \cdot$ Ryosuke Fujita $^{3} \cdot$ Tadashi Ueda $^{2} \cdot$ Jae Man Lee $^{5} \cdot$ Takahiro Kusakabe $^{4}(\mathbb{C}$
}

Received: 4 April 2021 / Accepted: 16 July 2021 / Published online: 25 July 2021

(c) The Author(s), under exclusive licence to Springer Science+Business Media, LLC, part of Springer Nature 2021

\begin{abstract}
COVID-19, caused by SARS-CoV-2, is currently spreading around the world and causing many casualties. Antibodies against such emerging infectious diseases are one of the important tools for basic viral research and the development of diagnostic and therapeutic agents. CR3022 is a monoclonal antibody against the receptor binding domain (RBD) of the spike protein (S protein) of SARS-CoV found in SARS patients, but it was also shown to have strong affinity for that of SARS-CoV-2. In this study, we produced large amounts of three formats of CR3022 antibodies (scFv, Fab and IgG) with high purity using a silkworm-baculovirus expression vector system. Furthermore, SPR measurements showed that the affinity of those silkwormproduced $\mathrm{IgG}$ antibodies to $\mathrm{S}$ protein was almost the same as that produced in mammalian expression system. These results indicate that the silkworm-baculovirus expression system is an excellent expression system for emerging infectious diseases that require urgent demand for diagnostic agents and therapeutic agents.
\end{abstract}

Keywords Silkworm-baculovirus expression vector system $\cdot$ CR3022 antibody $\cdot \mathrm{scFv} \cdot \mathrm{Fab} \cdot \mathrm{IgG} \cdot \mathrm{SARS}-\mathrm{CoV}-2 \cdot \mathrm{Spike}$ protein

\section{Introduction}

In December 2019, coronavirus disease 2019 (COVID-19) caused by the severe acute respiratory syndrome coronavirus 2 (SARS-CoV-2) broke out in Wuhan, China and

Takahiro Kusakabe

kusakabe@agr.kyushu-u.ac.jp

1 Laboratory of Insect Genome Science, Graduate School of Bioresource and Bioenvironmental Sciences, Kyushu University, Motooka 744, Nishi-ku, Fukuoka 819-0395, Japan

2 Laboratory of Protein Structure, Function and Design, Faculty of Pharmaceutical Sciences, Kyushu University, Higashi-ku, Fukuoka 812-8582, Japan

3 Laboratory of Sanitary Entomology, Faculty of Agriculture, Kyushu University, Motooka 744, Nishi-ku, Fukuoka 819-0395, Japan

4 Laboratory of Insect Genome Science, Faculty of Agriculture, Kyushu University, Motooka 744, Nishi-ku, Fukuoka 819-0395, Japan

5 Laboratory of Creative Science for Insect Industries, Faculty of Agriculture, Kyushu University, Motooka 744, Nishi-ku, Fukuoka 819-0395, Japan rapidly spread around the world [1]. In May 2020, the WHO recognized it as a pandemic, more than 106 million people infected and 2.3 million people dead as of February 10, 2020 [2]. In 2002 and 2012, two other human coronaviruses, SARS-CoV [3] and MERS-CoV [4], have spread wide area. These three coronaviruses belong to beta-coronaviruses, probably originated from bats, and have viral envelope with spike glycoprotein (S protein) [5-7]. The $S$ protein is the major viral antigen and binds the host receptors and mediates virus-host membrane fusion when the virus invades the host cells $[8,9]$. The structure and function of the SARS-CoV-2 S protein have been analyzed in detail by the previous studies [10] and revealed that its receptor binding domain (RBD) adopts receptor binding sensitive (open or up) or insensitive (close or down) conformations within S protein [11-13]. Both SARS-CoV-2 and SARS-CoV mainly use human ACE2 membrane protein as a receptor [9] and their amino acid sequences of RBD are highly conserved $73 \%$ [14].

The monoclonal antibody CR3022, a neutralizing antibody targeting the RBD domain of SARS-CoV, was isolated by screening using a phage display library constructed from blood of a convalescent SARS patient from Singapore 
$[15,16]$. Interestingly, the previous studies have shown that CR3022 is capable of binding to the RBD of SARS-CoV-2 in which 24 of the CR3022 buried region (28 residues) are conserved between SARS-CoV and SARS-CoV-2 [17]. Recent report also demonstrated that CR3022 neutralizes SARS-CoV-2 through a neutralization mechanism that is not detectable in some assays [18], although other studies showed that CR3022 does not neutralize SARS-CoV-2 probably due to a single mutation, A384P, among the four unconserved residues $[17,19]$. These studies suggest that CR3022 could be useful for therapeutic regent against COVID-19, especially in combination with other neutralizing antibodies. Structural and biochemical analyses revealed that the binding epitope of CR3022 does not overlap with that of a neutralizing antibody isolated from a SARS-CoV-2 patient, thus the multiple antibodies are able to bind to the $\mathrm{S}$ protein without competition [20,21].

In therapeutic and serological applications of antibodies, in addition to $\operatorname{IgG}$, which has high detection sensitivity and high affinity for antigens due to its avidity effect, $\mathrm{scFv}$ and Fab are used because of their simple structure, high productivity, and small molecular weight, which makes it easy to control chemical modification of proteins and fusion with large enzymes [22, 23]. Post-translational modifications are important for antibodies to have biological functions, especially glycosylation, and it has been reported that the lack of glycosylation actually lowers the affinity of antibodies to Fcy receptors [24]. The E. coli expression system is simple and capable of expressing a large amount of protein, but not suitable for IgG production due to lack of the post-translational modifications such as disulfide bonds and glycosylation. Hence, the IgG is typically produced by transfecting expression plasmids into mammalian cells, such as $\mathrm{CHO}$ cells or HEK293 cells [25, 26]. However, the selection of stable cell lines expressing high amount of $\mathrm{IgG}$ is time-consuming, and transfection of large amount of plasmid is expensive when the commercially available kits are used. The baculovirus expression vector system (BEVS) using cultured insect cells is suitable for expressing eukaryotic proteins because of its post-translational modification is similar to that for mammalian cells. The BEVS using silkworm (silkworm-BEVS) is a more efficient system than that using the insect cells for expressing heterologous proteins. It is easy to scale up without evaluating growth conditions; simply increasing the number of silkworms rearing. In fact, our laboratory has successfully used the silkworm-BEVS to produce a variety of useful proteins [27-29].

In this study, we proposed that silkworm-BEVS is effective for rapid delivery of therapeutic and diagnostic agents against emerging infectious diseases, using the production of recombinant CR3022 antibody as an example. We produced more than $1 \mathrm{mg}$ of CR3022 in different formats, scFv, Fab, and $\mathrm{IgG}$, from silkworm serum and evaluated its binding affinity to the S protein of SARS-CoV-2. The results showed that silkworm-BEVS was effective in producing high quality and functional CR3022 antibodies.

\section{Materials and Methods}

\section{Cell Culture and Silkworm Strain}

Insect culture cells, BmN (Bombyx mori-derived cells) cells (Funakoshi Inc.), were cultured at $27^{\circ} \mathrm{C}$ using IPL-41 insect medium (Sigma, St. Louis, MO) containing 10\% Fatal Bovine Serum (Gibco, Grand Island, NY). The f38 strain of silkworm used in this study was provided by the Genetic Resources Development Center, Faculty of Agriculture, Kyushu University supported by the National BioResource Project (NBRP). Silkworm larvae were reared by fresh mulberry leaves at 25 to $27^{\circ} \mathrm{C}$.

\section{Construction of Recombinant Baculovirus}

The single chain variable fragments (scFv) of CR3022 heavy chain (Hc) (GenBank: ABA54613.1) and light chain (Lc) (GenBank: ABA54614.1) linked by a flexible peptide linker $($ GGGGS $\times 3$ ) was chemically synthesized (Integrated DNA Technologies Inc.). To construct gateway-based entry clones, the coding region of $\operatorname{scFvs}\left(\mathrm{V}_{\mathrm{H}} \mathrm{V}_{\mathrm{L}}, \mathrm{V}_{\mathrm{L}} \mathrm{V}_{\mathrm{H}}\right)$ were amplified by polymerase chain reaction (PCR) with KOD-Plus-Neo DNA polymerase (TOYOBO, Tokyo, Japan) using the primer sets (VHVL-F, R and VLVH-F, R, Table 1). The SalI and XhoI-digested amplicons were inserted into the modified pENTR11 (XhoI-digested pENTRL21c-TEV-H8S amplicon; our laboratory stocks) vector by Ligation High (TOYOBO, Tokyo, Japan). As described in our previous report [27], the lobster L21 sequence (L21) was used to enhance translation, the silkworm $30 \mathrm{~K}$-signal peptide $(30 \mathrm{~K})$ to secrete CR3022 antibodies into silkworm sera, and the C-terminal His8-STREP double tag is used to facilitate purification. The resulting constructs were designated pENTR11-L21-30K$\mathrm{V}_{\mathrm{H}}(\mathrm{G} 4 \mathrm{~S}) \mathrm{V}_{\mathrm{L}}$-TEV-H8S and pENTR11-L21-30K-V $\mathrm{L}_{\mathrm{L}}(\mathrm{G} 4 \mathrm{~S})$ $\mathrm{V}_{\mathrm{H}}$-TEV-H8S, respectively. To generate the Fab (HFab and Lc) expression vectors, $\mathrm{C}_{\mathrm{H} 1}$ and $\mathrm{C}_{\mathrm{L}}$ region were obtained by PCR using the CH1-G-R, F and CL-G-R, F primer sets (Table 1) from the vector of our previous study [30], and then these regions were connected to $\mathrm{V}_{\mathrm{H}}$ and $\mathrm{V}_{\mathrm{L}}$ gene by the Gibson assembly method [31], respectively. Regarding the $\mathrm{Hc}$ of $\mathrm{IgG}(\mathrm{HFab}-\mathrm{Fc})$ expression vector, the $\mathrm{Fc}$ region was connected to the HFab by PCR using Fc-G-F and Fc$\mathrm{G}-\mathrm{R}$ primers in the same manner as above. The resulting constructs were designated pENTR11-L21-30K-HFab-TEVH8S, pENTR11-L21-30K-Lc-TEV-H8S, and pENTR11L21-30K-Hc-TEV-H8S respectively. As illustrated in Fig. $1 \mathrm{~b}$, the resulting constructs were then transferred to the 
Table 1 List of primers used in this study

\begin{tabular}{ll}
\hline Primer name & Primer sequence $\left(5^{\prime}-3^{\prime}\right)$ \\
\hline VHVL-F & CAAATGCAGTTGGTTCAGTCCGGTACTGAG \\
VHVL-R & ggggGTCGACTTAATTCCACTTTGGTGCCTTGGCCG \\
VLVH-F & GATATACAACTGACGCAGTCCCCAGACAG \\
VLVH-R & ggggCTCGAGACAGTGACTGTGGTTCCCTGTCCCATAC \\
CH1-G-F & AAGGCACCCTGGTCACAGTCTCCTCAGCCTCCACCAAGGGTCCATCGGTC \\
CH1-G-R & AGTACAGGTTTTCGCCTGCACTCGAGGCACAAGATTTGGGCTCAACTTTC \\
CL-G-F & GCACCAAAGTGGAAATTAAACGTACGGTGGCTGCACCATCTGTCTTCATC \\
CL-G-R & GCTTCAACAGGGGAGAGTGTTAAGCCTCGAGTGCAGGCGAAAACCTGTACTTC \\
Fc-G-F & AAGTTGAGCCCAAATCTTGTGACAAAACTCACACATGCCCACCGTGCCCA \\
Fc-G-R & GAGCCTCTCCCTGTCTCCGGGTAAGTCGAGTGCAGGCGAAAACCTGTACTTCC \\
\hline
\end{tabular}

modified pDEST8/v-cath-EGFP vector (Invitrogen, Carlsbad, CA, our laboratory stock) by the Gateway LR reaction to generate baculovirus transfer plasmid following the manufacturer's protocol. The five recombinant baculoviruses were created using BmNPV/T3 bacmid DNA according to the previous study [32]. The bacmid DNA was then transfected into the BmN cell using Avalanche®-Everyday transfection reagent (EZ Biosystems, College Park, MD, USA) to produce the recombinant virus particles. The culture supernatant was harvested as the P1 virus on the 5th day after cell transfection. The high-titer virus (P3) stock $\left(\sim 1 \times 10^{7}\right.$ plaque-forming unit $/ \mathrm{ml}$ ) was prepared through a serial infection of baculovirus in cultured cells. All viruses for silkworm infections were kept at $4{ }^{\circ} \mathrm{C}$ in the dark until use.

\section{Expression of Recombinant scFv, Fab and lgG in Silkworm Hemolymph}

The recombinant baculovirus expressing the $\operatorname{scFv}\left(\sim 1 \times 10^{5}\right.$ plaque-forming unit per larvae) were injected into the 5 th instar silkworm larvae (day 3). In the case of Fab and IgG, the two recombinant baculoviruses, expressing HFab and Lc or $\mathrm{Hc}$ and Lc, respectively, in different ratio were infected to BmN cells and all samples were prepared based on the method according to the previous study [27]. After optimizing the co-infection ratio of two recombinant baculoviruses using $\mathrm{BmN}$ cells, the recombinant baculoviruses expressing $\mathrm{HFab}$ and $\mathrm{Lc}$ or $\mathrm{Hc}$ and Lc were injected into the 5th instar silkworm larvae (day 3) at a ratio of 3:1. Silkworm hemolymph was collected into a tube containing $20 \mathrm{mM}$ 1-phenyl2-thiourea at $4 \mathrm{dpi}$ and centrifuged at $9000 \mathrm{rpm}$ for $10 \mathrm{~min}$ at $4{ }^{\circ} \mathrm{C}$ to remove insoluble matter. The supernatant sample was immediately frozen at $-80^{\circ} \mathrm{C}$.

\section{SDS-PAGE and Western Blotting Analysis}

The expression of CR3022 antibodies in all samples was analyzed using sodium dodecyl sulfate-polyacrylamide gel electrophoresis (SDS-PAGE) followed by Western blotting analysis. The samples were separated by $5-20 \%$ or $12 \%$ SDS-PAGE under the reducing or non-reducing conditions and transferred onto polyvinylidene difluoride (PVDF) membrane (Millipore, Billerica, MA), and further blocked in TBST buffer (20 mM Tris-HCl pH 7.6; $500 \mathrm{mM} \mathrm{NaCl}$; $0.1 \%$ w/v Tween-20) with $5 \%$ w/v skim milk. The membrane was incubated with HisProbe-HRP (1:5000) (Thermo Fisher Scientific, Waltham, MA) at $4{ }^{\circ} \mathrm{C}$. The specific protein bands were visualized using the Super Signal West Pico Chemiluminescent Substrate (Thermo Fisher Scientific, Waltham, MA).

\section{Purification of Recombinant CR3022 Antibodies}

The purification procedure was performed using HisTrap excel column (GE Healthcare Bioscience, Piscataway, NJ) and Strep-Tactin HP column (IBA GmbH, Germany). This protocol for two-step affinity chromatography was previously optimized in our laboratory [27]. The clarified silkworm serum was diluted up to $50 \mathrm{~mL}$ by binding buffer (20 mM Tris- $\mathrm{HCl} \mathrm{pH} \mathrm{7.5;} 0.5 \mathrm{M} \mathrm{NaCl}$ ), and filtered through $0.45 \mu \mathrm{m}$ filters (Millipore, Billerica, MA) after centrifuged at $9000 \mathrm{rpm}$ for $10 \mathrm{~min}$ at $4{ }^{\circ} \mathrm{C}$. The sample was loaded onto a $5 \mathrm{~mL}$ HisTrap excel column, and after washing with $25 \mathrm{~mL}$ binding buffer containing $30 \mathrm{mM}$ imidazole, the proteins were eluted with $12 \mathrm{~mL}$ and $15 \mathrm{~mL}$ binding buffer containing $100 \mathrm{mM}$ and $500 \mathrm{mM}$ imidazole, respectively. The eluted fractions containing antibodies were collected and concentrated to $5 \mathrm{~mL}$ by ultrafiltration using Amicon Ultra-15 $10 \mathrm{~K}$ filters (Millipore, Billerica, MA).

Then, the sample removing excess imidazole was further diluted up to $50 \mathrm{~mL}$ by PBS and load onto a $5 \mathrm{~mL}$ StrepTactin column. After the wash with $25 \mathrm{~mL}$ of PBS, the proteins were eluted with $24 \mathrm{~mL}$ of PBS supplemented with $2.5 \mathrm{mM}$ desthiobiotin, then the fractions containing antibodies were collected and concentrated to $2 \mathrm{~mL}$ by ultrafiltration using Amicon Ultra-15 $10 \mathrm{~K}$ filters. The concentrated sample was dialyzed by PBS, and the final concentration of 
a
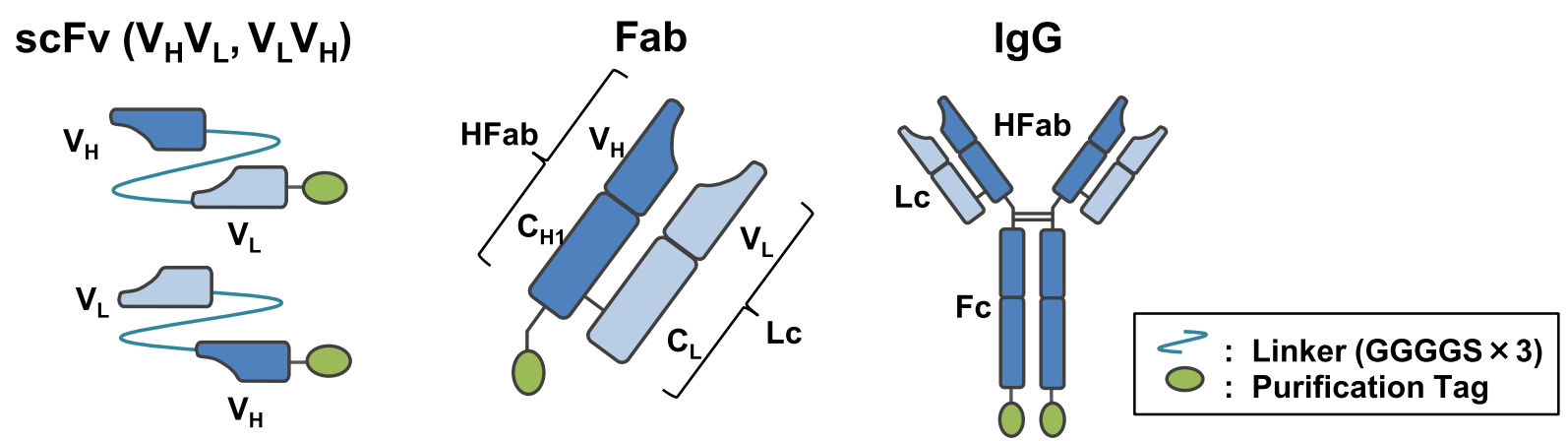

b

$\operatorname{scFv}\left(\mathrm{V}_{\mathrm{H}} \mathrm{V}_{\mathrm{L}}\right)$

PDEST8-L21-30k- $\mathrm{V}_{\mathrm{H}}(\mathrm{G} 4 \mathrm{~S}) \mathrm{V}_{\mathrm{L}}-\mathrm{TEV}-\mathrm{H} 8 \mathrm{~S}$

Linker: GGGGS $\times 3$

\begin{tabular}{|l|l|l|l|l|l|l|l|}
\hline PH & $B 1$ \\
\hline
\end{tabular} \begin{tabular}{|l|l|l|l|l|l|l|}
\hline L21 & $30 K$ & $V_{H}$ & $V_{L}$ & TEV & 8xHis & Strep \\
\hline
\end{tabular}

$\operatorname{scFv}\left(\mathbf{V}_{\mathbf{L}} \mathbf{V}_{\mathrm{H}}\right)$

pDEST8-L21-30k-V $\mathrm{V}_{\mathrm{L}}(\mathrm{G} 4 \mathrm{~S}) \mathrm{V}_{\mathrm{H}}$-TEV-H8S

Linker : GGGGS $\times 3$

\begin{tabular}{|l|l|l|l|l|l|l|l|l|}
\hline PH & B1 \\
\hline
\end{tabular} \begin{tabular}{|l|l|l|l|l|l|l|l|}
\hline L21 & $30 K$ & $V_{L}$ & $V_{H}$ & TEV & 8xHis & Strep \\
\hline
\end{tabular}

Fab

pDEST8-L21-30k-HFab-TEV-H8S

\begin{tabular}{|l|l|l|l|l|l|l|l|}
\hline PH & B1 & L21 & $30 K$ & HFab & TEV & 8xHis & Strep \\
\hline
\end{tabular}

PDEST8-L21-30k-LC

\begin{tabular}{|l|l|l|l|l|l|l|l|l|l|}
\hline LH & L21 & $30 K$ & LC & SV40 \\
\hline
\end{tabular}

$\lg G$

PDEST8-L21-30k-HC-TEV-H8S

\begin{tabular}{|l|l|l|l|l|l|l|l|}
\hline PH & B1 \\
\hline
\end{tabular}

PDEST8-L21-30k-Lc

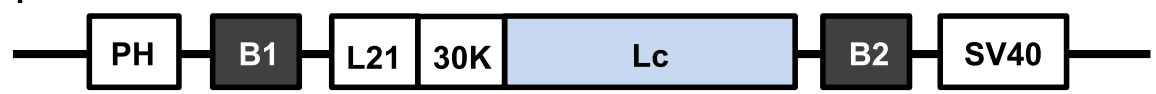


4Fig. 1 a Schematic diagram of the three formats of CR3022 antibodies (Hc: heavy chain, Lc: light chain, HFab: N-terminal half of one heavy chain). In the scFvs $\left(\mathrm{V}_{\mathrm{H}} \mathrm{V}_{\mathrm{L}}\right.$ and $\left.\mathrm{V}_{\mathrm{L}} \mathrm{V}_{\mathrm{H}}\right)$, the antibody regions of the $\mathrm{V}_{\mathrm{H}}$ and $\mathrm{V}_{\mathrm{L}}$ are linked by a linker $\left(3 \times \mathrm{G}_{4} \mathrm{~S}\right)$. All three formats have a purification tag for facilitating purification. b Construction of the recombinant baculoviruses expressing the three formats of CR3022 antibodies ( $\mathrm{scFv}, \mathrm{Fab}$ and $\mathrm{IgG}$ ). The expression of them were under the control of the polyhedrin promoter (PH) and follow by an SV40 polyadenylation signal (SV40). B1 and B2: recombination sites for Gateway cloning; L21: leader sequence for enhancing translation efficiency; $30 \mathrm{~K}$ : signal peptide of silkworm $30 \mathrm{kDa}$ protein; TEV: tobacco etch virus protease cleavage site; ${ }_{8 \mathrm{x}} \mathrm{His}$ : $8 \times$ Histidine tag; Strep: Strep tag

the protein was quantified by ImageJ using bovine serum albumin (BSA) as standard.

\section{Spike-Antibody Interaction Analysis by Surface Plasmon Resonance (SPR) Experiments}

SPR experiments were performed using a Biacore X100 (GE Healthcare Bioscience, Piscataway, NJ) at $25{ }^{\circ} \mathrm{C}$. SARSCoV-2 spike proteins were immobilized on a CM5 sensor chip (Cytiva, Tokyo, Japan) using standard amine-coupling chemistry. This SARS-CoV-2 Spike protein was expressed using a silkworm-baculovirus expression vector system and purified from silkworm serum using the two-step chromatography as well as the recombinant antibodies. Immobilization densities on flow cell 2 are $\sim 2000$ for CR3022 $\mathrm{V}_{\mathrm{H}} \mathrm{V}_{\mathrm{L}}$, $\mathrm{V}_{\mathrm{L}} \mathrm{V}_{\mathrm{H}}$, and Fab and $\sim 1000 \mathrm{RU}$ for IgG, respectively. Flow cell 1 was left blank to serve as a reference surface. All the surfaces were blocked with $1 \mathrm{M}$ ethanolamine, $\mathrm{pH}$ 8.5. A two-fold dilution series of the antibodies (15.6-250 nM of $\mathrm{V}_{\mathrm{H}} \mathrm{V}_{\mathrm{L}}, \mathrm{V}_{\mathrm{L}} \mathrm{V}_{\mathrm{H}}$ and Fab, 0.63-10 $\mathrm{nM}$ of IgG) diluted in a running buffer (PBS with $0.005 \%$ Tween-20) was injected with a flow rate of $30 \mu \mathrm{L} / \mathrm{min}$ for $3 \mathrm{~min}$ followed by $10 \mathrm{~min}$ of dissociation step. The surfaces were regenerated with $30 \mathrm{~s}$ injection of $10 \mathrm{mM}$ Gly-HCl, pH 2.5 followed by $30 \mathrm{~s}$ injection of $3 \mathrm{M} \mathrm{MgCl}_{2}$. The data were fit to a simple 1:1 interaction model using the global data analysis available within Biacore X100 evaluation software.

\section{ELISA}

ELISA was performed to examine the binding affinity of CR3022 IgG to $\mathrm{S}$ protein. The 96-well plate were coated with four concentrations of $\mathrm{S}$ protein $(0.1,1,10,100 \mathrm{ng})$ and incubated overnight at $4{ }^{\circ} \mathrm{C}$. The plates were washed four times with $300 \mu \mathrm{L}$ PBST (PBS with $0.1 \%$ Tween-20), blocked with $5 \%$ skim milk in PBST for $2 \mathrm{~h}$ at room temperature, and then the four concentrations of purified CR3022 $\operatorname{IgG}(0.01,0.1,1,10 \mu \mathrm{g} / \mathrm{mL})$ were added to the wells and incubated for $1 \mathrm{~h}$ at $37{ }^{\circ} \mathrm{C}$. The plates were washed four times and incubated with Anti-Human IgG Fc which conjected with HRP (1:10,000) (\#ab98624, Abcam, Cambridge,
$\mathrm{UK})$. After $1 \mathrm{~h}$ incubation at $37^{\circ} \mathrm{C}$, the plate was washed, developed with TMB substrate and the reaction was stopped by the addition of $2 \mathrm{~N} \mathrm{H}_{2} \mathrm{SO}_{4}$. Then the absorbance read at $450 \mathrm{~nm}$ and $620 \mathrm{~nm}$.

\section{Results}

\section{Construction of the Recombinant Baculoviruses and Expression of scFv, Fab and IgG}

To establish the low cost and efficient expression system of CR3022 scFv, Fab and IgG, we have generated 5 recombinant baculoviruses shown in Fig. $1 \mathrm{~b}$ as described under the Materials and methods. The Heavy chain (Hc) and Light chain (Lc) of CR3022 sequence were codon-optimized for $B$. mori s and were chemically synthesized. A signal peptide of a silkworm $30 \mathrm{kDa}$ protein (30 K-signal peptide) was fused to the N-termini of the target proteins, and a lobster L21 sequence was inserted upstream of the $30 \mathrm{~K}$-signal peptide to increase the amount of protein translation. In addition, TEV cleavage site, His and STREP tag were fused to the C-termini of all constructs for purification, except for the Lc expression vector.

For scFvs $\left(\mathrm{V}_{\mathrm{H}} \mathrm{V}_{\mathrm{L}}, \mathrm{V}_{\mathrm{L}} \mathrm{V}_{\mathrm{H}}\right)$ expression, the 5 th instar silkworm larvae were infected with the corresponding recombinant baculoviruses. The expression of these antibodies in silkworm hemolymph was then confirmed by Western blotting analysis. As shown in Fig. $2 \mathrm{a}, \mathrm{b}, \mathrm{V}_{\mathrm{H}} \mathrm{V}_{\mathrm{L}}$ and $\mathrm{V}_{\mathrm{L}} \mathrm{V}_{\mathrm{H}}$ were expressed in silkworm hemolymph and their predicted molecular weight were approximately $30 \mathrm{kDa}$ regardless of reducing or non-reducing conditions, respectively.

To optimize the expression of Fab and IgG as heterodimer or heterotetramer, respectively, we varied the ratio of two viruses co-infected into BmN cells and confirmed the expression of them by Western blotting at $3 \mathrm{dpi}$ (the virus combinations to express Fab and IgG are shown in Fig. 1b). Under the non-reducing conditions, it is demonstrated that the optimal infection ratio of the two recombinant baculoviruses, HFab and Lc for Fab or Hc and $\mathrm{Lc}$ for IgG, was $3: 1$ in the medium of cultured BmN cells (Supplemental Fig. S1a, b). Therefore, this 3:1 of recombinant baculoviruses co-infection ratio was used for the efficient expression of Fab and $\mathrm{IgG}$ in silkworm larvae. As shown in Fig. 2a, Lanes 3 and 4, the expression of the HFab of Fab or Hc of IgG with molecular weight of approximately 27 or $53 \mathrm{kDa}$, respectively, were confirmed by Western blotting (reducing conditions) in hemolymph of the 5 th instar larvae at 4dpi. Furthermore, the assembled Fab and IgG were observed in the non-reducing conditions (Fig. 2b, Lanes 3 and 4). When the hemolymph of silkworm $\mathrm{f} 38$ strain was subjected to Western blotting analysis using His-probe, the non-specific 


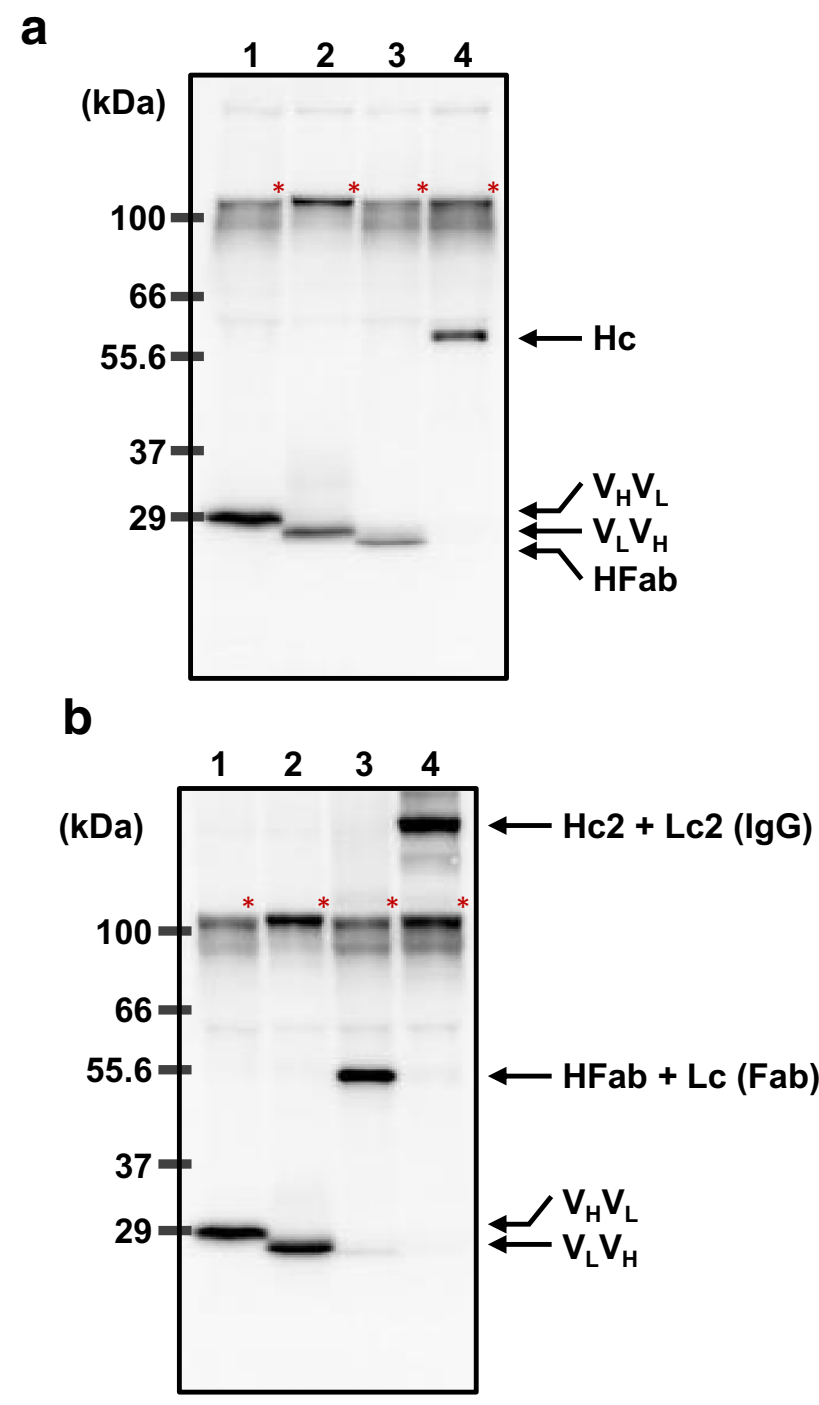

Fig. 2 Expression of scFvs $\left(\mathrm{V}_{\mathrm{H}} \mathrm{V}_{\mathrm{L}}\right.$ and $\left.\mathrm{V}_{\mathrm{L}} \mathrm{V}_{\mathrm{H}}\right)$, Fab and $\mathrm{IgG}$ in silkworm hemolymph at 4 dpi under the reducing condition (a) and nonreducing condition (b), respectively (Lane 1: $\mathrm{V}_{\mathrm{H}} \mathrm{V}_{\mathrm{L}}$, Lane 2: $\mathrm{V}_{\mathrm{L}} \mathrm{V}_{\mathrm{H}}$, Lane 3: Fab, Lane 4: IgG). These expressions were confirmed by Western blotting using HisProbe

background signal was detected around $100 \mathrm{kDa}$ in all lanes (Fig. 2, asterisk).

\section{Purification of CR3022 Recombinant Antibodies from Silkworm Hemolymph}

All four CR3022-derived antibodies successfully expressed in silkworm hemolymph were purified by two-step affinity chromatography. As shown in Fig. 3, the affinity purification through His tag and Strep tag chromatography is simple and highly efficient; CBB staining of SDS-PAGE gel clearly shows that the recombinant CR3022 antibodies could be purified with high purity. In the cases of Fab and $\mathrm{IgG}$, the Lc without purification tags were detected in the same elution fractions with $\mathrm{HFab}$ and $\mathrm{Hc}$ at a molecular ratio of approximately 1:1 (Fig. 3c, d), suggesting that disulfide bonds between Lc and HFab or Hc are correctly formed. Moreover, in the Histidine affinity purification, the scFvs and Fab begin to elute in the binding buffer containing $100 \mathrm{mM}$ imidazole, whereas most of the IgG elutes in the binding buffer containing $500 \mathrm{mM}$ imidazole (Fig. 3d, Lane 5 and 6). Since the IgG molecule forming homodimer by disulfide bonds has two purification tags, it is expected to have strong binding affinity to nickel conjected agarose beads. These purified proteins were dialyzed against $1 \times$ PBS and quantified. As a result, $2.34 \mathrm{mg}$ of $\mathrm{V}_{\mathrm{H}} \mathrm{V}_{\mathrm{L}}, 2.64 \mathrm{mg}$ of $\mathrm{V}_{\mathrm{L}} \mathrm{V}_{\mathrm{H}}, 1.44 \mathrm{mg}$ of $\mathrm{Fab}$, and $1.30 \mathrm{mg}$ of IgG were purified from $10 \mathrm{ml}$ of silkworm hemolymph, and the SDS-PAGE verifications for each purified antibody demonstrated that they were achieved in good purity, $95 \%$ for $\mathrm{V}_{\mathrm{H}} \mathrm{V}_{\mathrm{L}}, 98 \%$ for $\mathrm{V}_{\mathrm{L}} \mathrm{V}_{\mathrm{H}}, 93 \%$ for Fab, and $84 \%$ for IgG, respectively, as judged by image analysis of gels.

\section{Binding Analysis of CR3022 Recombinant Antibodies}

The binding affinity of CR3022 scFvs, Fab and IgG with SARS-CoV-2 Spike (S) protein was measured using surface plasmon resonance (SPR) analysis (Fig. 4). The dissociation constants $\left(K_{\mathrm{D}}\right)$ of the $\mathrm{V}_{\mathrm{H}} \mathrm{V}_{\mathrm{L}}, \mathrm{V}_{\mathrm{L}} \mathrm{V}_{\mathrm{H}}$ and Fab with the ectodomain of SARS-CoV-2 S protein (a.a. 1-1208; without furin cleavage site (residues 682-685) and proline substitutions at residues 986 and 987) [33] were $20.1 \mathrm{nM}$, $27.8 \mathrm{nM}$ and $45.4 \mathrm{nM}$, respectively (Fig. $4 \mathrm{a}-\mathrm{c}$ ). On the other hand, CR3022 exhibited a much higher affinity for $\mathrm{S}$ protein with the $K_{\mathrm{D}}$ of $0.21 \mathrm{nM}$, which was approximately 50-100 greater than Fab and scFvs (Fig. 4d). Furthermore, to evaluate whether the CR3022 IgG produced in silkworm are usable for ELISA, different amounts of S protein (0.1, 1,10 , and $100 \mathrm{ng}$ ) were immobilized on a 96-well plate and its binding with CR3022 IgG was measured. As shown in Fig. 5, the CR3022 IgG was able to detect SARS-CoV-2 S protein in a dose-dependent manner. With $100 \mathrm{ng}$ of S protein on the plate, the binding signal reached the plateau at a concentration of $1 \mu \mathrm{g} / \mathrm{mL}$ CR3022 IgG. In addition, when using $10 \mu \mathrm{g} / \mathrm{mL}$ IgG, the detection limit was $\sim 100 \mathrm{pg}$ of S protein (Fig. 5, inlet).

\section{Discussion}

Upon the emerging of infectious diseases spreading all over the world, it is important to urgently proceed with basic scientific research on such pathogenic the viruses and microorganisms. These basic studies are indispensable for the development of diagnostic and therapeutic agents to prevent the diseases and protect our health. In particular, antibodies 
a

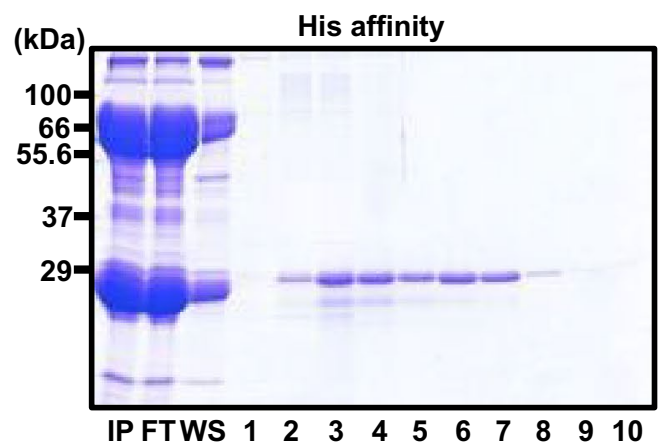

b

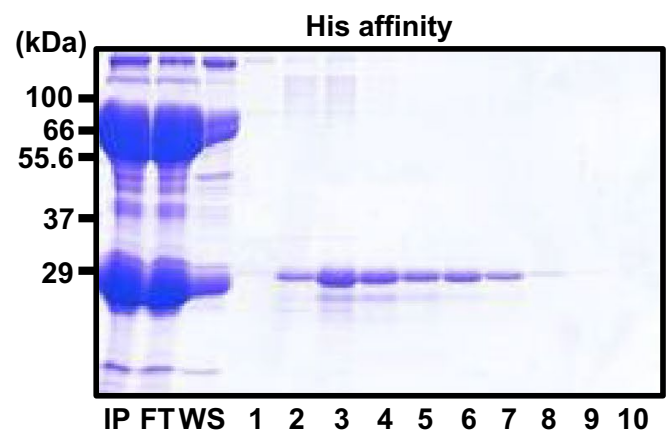

C

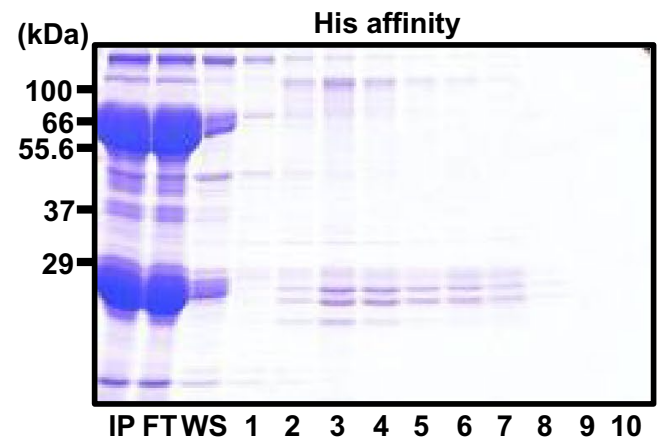

d

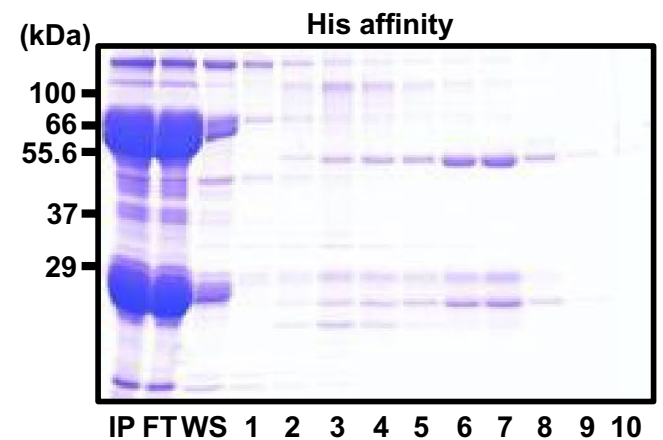

Fig. 3 Purification of the CR3022 antibodies from hemolymph of silkworm larvae infected or co-infected with recombinant baculoviruses using the two-step affinity chromatography $\left(\mathbf{a} \mathrm{V}_{\mathrm{H}} \mathrm{V}_{\mathrm{L}}, \mathbf{b} \mathrm{V}_{\mathrm{L}} \mathrm{V}_{\mathrm{H}}\right.$, c $\mathrm{Fab}, \mathbf{d} \mathrm{IgG}$ ) as described in Materials and Methods. The arrows indicate the each of recombinant antibodies. IP: input; FT: flow-
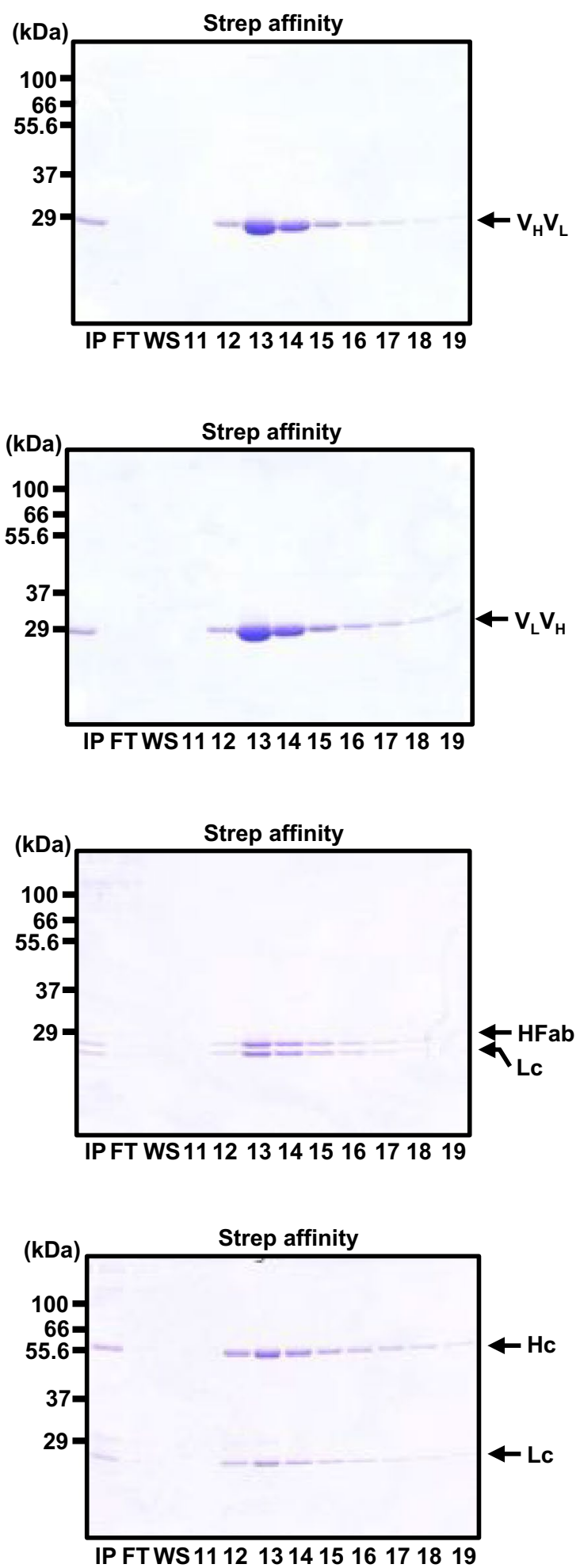

through; WS: wash fraction; lanes 1-4: elution fractions by $100 \mathrm{mM}$ imidazole; lanes 5-10: elution fractions by $500 \mathrm{mM}$ imidazole; lanes 11-19: elution fractions by $2.5 \mathrm{mM}$ desthiobiotin. Protein samples from each step were resolved in 12\% SDS-PAGE and visualized by Coomassie Brilliant Blue (CBB) R-250 staining 

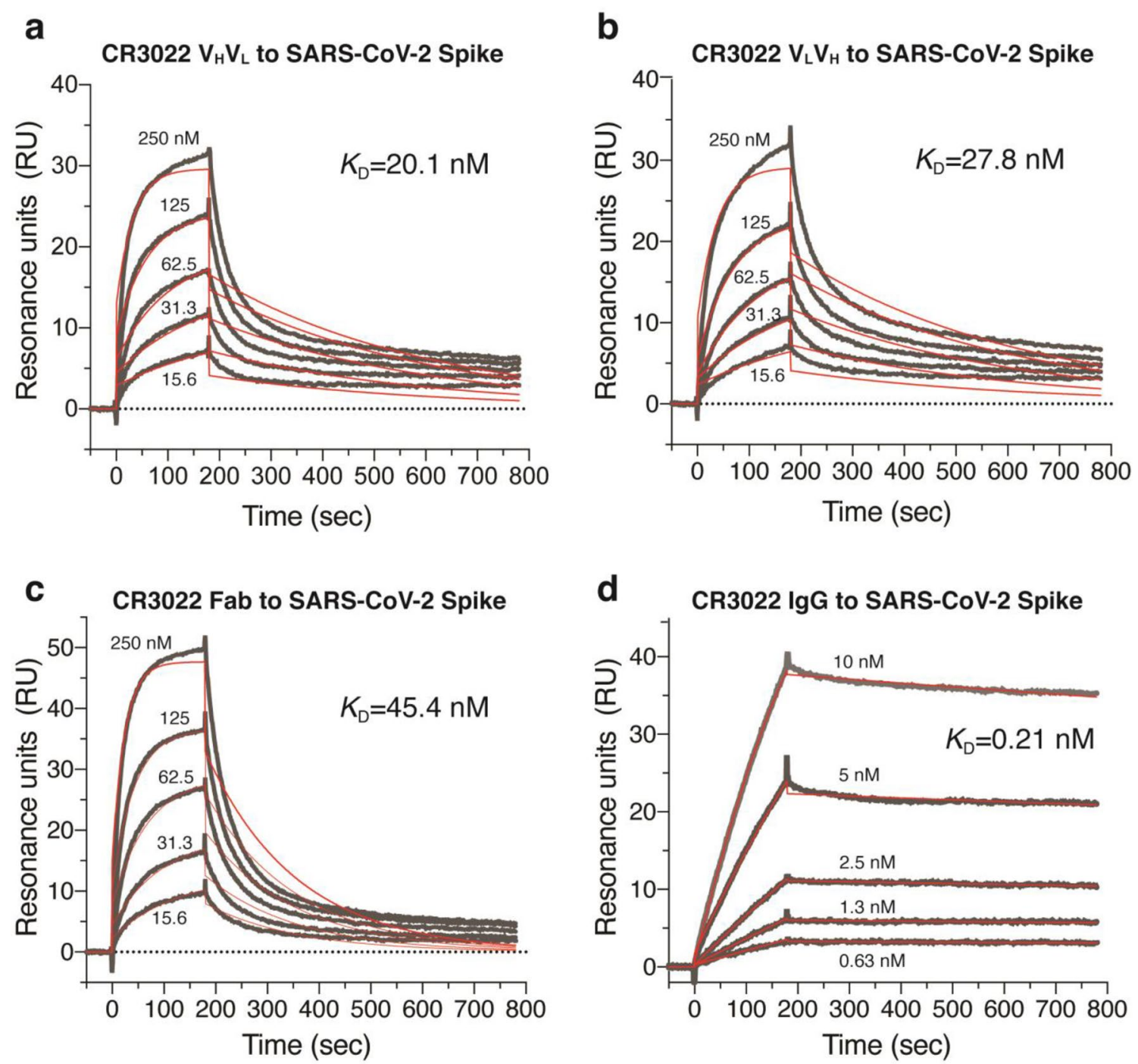

Fig. 4 Binding affinity of CR3022 antibodies with $\mathrm{S}$ protein. The binding affinity of CR3022 $\mathrm{V}_{\mathrm{H}} \mathrm{V}_{\mathrm{L}}$ (a), $\mathrm{V}_{\mathrm{L}} \mathrm{V}_{\mathrm{H}}$ (b), Fab (c) and $\mathrm{IgG}$ (d) with $\mathrm{S}$ protein were measured using surface plasmon resonance

specific for pathogenic microorganisms are one of the most important tools in these studies.

Using a Silkworm-BEVS, we produced three formats of CR3022 antibodies (scFvs, Fab and IgG) which have been first reported as a neutralizing antibody against the RBD of SARS-CoV and recently reported to bind strongly to that of SARS-CoV-2. The S protein, the major antigen of SARSCoV-2, is very similar to that of the previously prevalent SARS-CoV, with $73 \%$ homology in amino acid sequences of RBD, a target for diagnostic and therapeutic agents [34].

In this study, we produced more than $1 \mathrm{mg}$ of four different recombinant CR3022 antibodies from $10 \mathrm{~mL}$ of silkworm hemolymph within a month (Fig. 3). Several expression systems were used to produce human $\mathrm{scFv}$ [35-37] and the $E$. coli expression system is one of the most suitable as described in Materials and Methods. The data were fit to a simple $1: 1$ interaction model using the global data analysis available within Biacore X100 evaluation software

expression systems for mass production of scFv [38]. However, it is time-consuming to purify and refold the scFv expressed in E. coli from the inclusion body [39], whereas the silkworm-BEVS is capable of producing scFvs comparable to the $E$. coli expression system without refolding. In addition, it is very difficult to produce Fab or IgG in E. coli which lacks post-translational modifications. Cultured mammalian cells also provide a platform for producing recombinant antibodies in large scale, but the screening of cell lines with high-expression and the modulation of culture conditions are time-consuming (minimum 12 months) [25]. Using silkworm-BEVS, it is possible to express and purify the biologically active Fab and $\mathrm{IgG}$ with correct disulfide bond formation in a much shorter time than mammalian cell expression systems. For CR3022 IgG, it has been reported 
Fig. 5 Binding affinity of CR3022 IgG with S protein in ELISA. The different concentrations of CR3022 $\operatorname{IgG}(0.01,0.1$, $1,10 \mu \mathrm{g} / \mathrm{mL}$ ) were incubated with the plates coated with the different concentrations of $S$ protein $(0.1,1,10$, and $100 \mathrm{ng})$, and then detected by an HRPconjugated Anti-Human IgG Fc

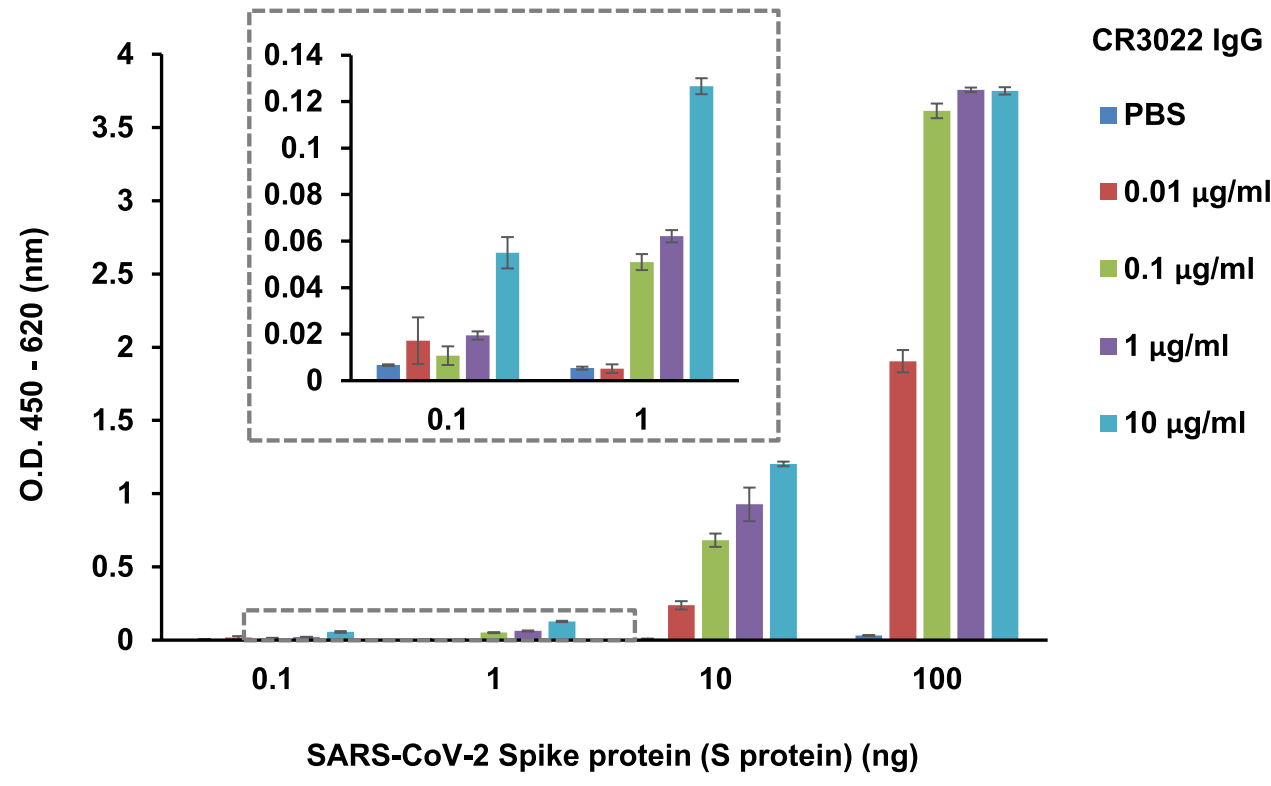

that an expression level of $130 \mu \mathrm{g}$ per gram of fresh leaf weight can be obtained using a transient expression system in plants [40]. In this study, $130 \mu \mathrm{g}$ of purified CR3022 IgG was eventually purified and recovered from $1 \mathrm{~mL}$ of silkworm serum using silkworm-BEVS. Although it is difficult to make a simple comparison, these results suggest that the expression level is comparable or more equivalent to that produced in plants.

The SPR measurement showed that CR3022 IgG has higher affinity $\left(K_{\mathrm{D}}=0.21 \mathrm{nM}\right)$ than $\mathrm{V}_{\mathrm{H}} \mathrm{V}_{\mathrm{L}}, \mathrm{V}_{\mathrm{L}} \mathrm{V}_{\mathrm{H}}$ and Fab $\left(K_{\mathrm{D}}=20.1 \mathrm{nM}, 27.8 \mathrm{nM}\right.$ and $45.4 \mathrm{nM}$, respectively). The previous study measuring the affinity of CR3022 antibodies produced using the different expression system [14] revealed that the $\mathrm{CR} 3022 \mathrm{scFv}$ produced by $E$. coli had a $K_{\mathrm{D}}$ of $6.3 \mathrm{nM}$ with the RBD, which is higher than that produced by the silkworm-BEVS. This result may be caused by the differences in the antigens or in coupling methods; the $\mathrm{S}$ proteins were immobilized by amine-coupling in this study, and RBD was enzymatic biotinylated and immobilized onto a strept-avidin chip in the other studies. The $\mathrm{V}_{\mathrm{H}} \mathrm{V}_{\mathrm{L}}$ and $\mathrm{V}_{\mathrm{L}} \mathrm{V}_{\mathrm{H}}$ of CR3022 produced using silkworm-BEVS showed almost equivalent productivity of $2.34 \mathrm{mg}$ and $2.64 \mathrm{mg}$ per $10 \mathrm{~mL}$ of silkworm serum, respectively, while the affinity of $\mathrm{V}_{\mathrm{H}} \mathrm{V}_{\mathrm{L}}$ was slightly higher than that of $\mathrm{V}_{\mathrm{L}} \mathrm{V}_{\mathrm{H}}$. Previous studies have shown that the productivity and affinity of $\mathrm{V}_{\mathrm{H}} \mathrm{V}_{\mathrm{L}}$ and $\mathrm{V}_{\mathrm{L}} \mathrm{V}_{\mathrm{H}}$ differ depending on the type of antibody [41, 42], and for CR3022, $\mathrm{V}_{\mathrm{H}} \mathrm{V}_{\mathrm{L}}$ was considered to be a more suitable form of $\mathrm{scFv}$ for diagnostic and pharmaceutical applications than $\mathrm{V}_{\mathrm{L}} \mathrm{V}_{\mathrm{H}}$. It was also reported that the affinity of CR3022 Fab or IgG produced in mammalian cells with the RBD is $115 \mathrm{nM}$ and $<0.1 \mathrm{nM}$, respectively [17]. The affinity of CR3022 IgG produced using silkworm-BEVS was almost the same as that in the mammalian cells at $0.21 \mathrm{nM}$. In contrast, the $K_{\mathrm{D}}$ of
CR3022 Fab produced using silkworm-BEVS (45.4 nM) is higher than that of produced using mammalian system (115 nM). The CR3022 Fab and IgG used in this study were designed to have two disulfide bonds (usually one) connecting $\mathrm{C}_{\mathrm{H} 1}$ and $\mathrm{C}_{\mathrm{L}}$ to enhance the productivity of the recombinant antibodies. The $K_{\mathrm{D}}$ of CR3022 Fab with two disulfide bonds produced in this study was 2.5 -fold lower than that of mammalian cell-produced CR3022 Fab with single disulfide bond, suggesting that an additional disulfide bond probably contributes to increase the binding activity of CR3022 Fab in the absence of Fc regions.

Dose-dependent binding of the CR3022 IgG produced using silkworm-BEVS were shown by ELISA, but the reaction plateaued at a concentration of $100 \mathrm{ng}$ of $\mathrm{S}$ protein per well (96-well plate). The detection limit in ELISA was $\sim 100 \mathrm{pg}(0.7 \mathrm{pM})$ of $\mathrm{S}$ protein, which is less sensitive than other detection systems, as described in previous report [43], and would not be enough to detect the virus protein in sera with low viral titers in early infected patients. To use the IgG as a diagnostic reagent to detect the SARS-CoV-2 from patient sera, the sensitivity of detection system such as an immunochromatography system needs to be improved further. Since several SARS-CoV-2 antibodies recognizing the different regions of RBD were reported [20, 21], it is possible to develop a highly sensitive detection system by combining the multiple antibodies without competition for epitope binding.

Recently, the antibody-dependent cellular cytotoxicity (ADCC) activity of monoclonal antibodies against several viruses-infected cells has been highlighted because of its potential to decrease viral replication and reduce clinical symptoms [44, 45]. ADCC is one of the antiviral activity that induces the cellular cytotoxicity through a natural 
killer (NK) cell expressing Fc receptors, which binds to Fc region of IgG. [46]. Therefore, this ability of antibodies to induce strong ADCC would be advantageous when used as therapeutic agents. The induction of ADCC is enhanced by the lack of $\alpha$-1,6-fucose in the N-linked glycan (Asn-297 in the $\mathrm{C}_{\mathrm{H} 2}$ domain) of the $\mathrm{Fc}$ region [47, 48]. Previous studies showed that the antibodies secreted form the transgenic silkworm lack this fucose and is demonstrated to have the ability to induce the strong ADCC [49]. Considering these reports, it is highly likely that CR3022 IgG produced using silkworm-BEVS can induce stronger ADCC than those produced by other expression systems, and is expected to be highly effective in clinical applications.

\section{Conclusion}

In conclusion, we demonstrated that the silkworm-BEVS can produce antibodies in three different formats of CR3022 easily in a short-term. Furthermore, the purified CR3022 antibodies showed almost the same affinity for the $\mathrm{S}$ protein as those produced in mammalian cells. Thus, our study suggests that the silkworm-BEVS is suitable as an expression system for producing diagnostic and therapeutic agents that can rapidly respond to emerging of infectious diseases including COVID-19.

Supplementary Information The online version contains supplementary material available at https://doi.org/10.1007/s12033-021-00373-0.

Acknowledgements This work was supported in part by Cabinet Office, Government of Japan, Cross-ministerial Strategic Innovation Promotion Program (SIP), "Technologies for Smart Bio-industry and Agriculture" (funding agency: Bio-oriented Technology Research Advancement Institution, NARO). This work was partially supported by Platform Project for Supporting Drug Discovery and Life Science Research (Basis for Supporting Innovative Drug Discovery and Life Science Research (BINDS)) from Japan Agency for Medical Research and Development (AMED) under Grant Number JP20am0101091.

\section{Declarations}

Conflict of interest The authors declare that they have no conflict of interest.

\section{References}

1. Zu, Z. Y., Jiang, M. D., Xu, P. P., Chen, W., Ni, Q. Q., Lu, G. M., \& Zhang, L. J. (2020). Coronavirus disease 2019 (COVID-19): A perspective from China. Radiology. https://doi.org/10.1148/radiol. 2020200490

2. Coronavirus disease (COVID-19). (n.d.). Retrieved February 26, 2021, from https://www.who.int/emergencies/diseases/novelcoronavirus-2019.

3. Drosten, C., Günther, S., Preiser, W., van der Werf, S., Brodt, H.-R., Becker, S., et al. (2003). Identification of a novel
Coronavirus in patients with severe acute respiratory syndrome. New England Journal of Medicine, 348(20), 1967-1976. https:// doi.org/10.1056/nejmoa030747

4. Zaki, A. M., van Boheemen, S., Bestebroer, T. M., Osterhaus, A. D. M. E., \& Fouchier, R. A. M. (2012). Isolation of a novel Coronavirus from a man with pneumonia in Saudi Arabia. New England Journal of Medicine, 367(19), 1814-1820. https://doi. org/10.1056/nejmoa1211721

5. Fan, Y., Zhao, K., Shi, Z. L., \& Zhou, P. (2019). Bat coronaviruses in China. Viruses. 11(3), 210

6. Cui, J., Li, F., \& Shi, Z. L. (2019). Origin and evolution of pathogenic coronaviruses. Nature Reviews Microbiology, 17(3), 181-192. https://doi.org/10.1038/s41579-018-0118-9

7. Zhou, P., Yang, X. L., Wang, X. G., Hu, B., Zhang, L., Zhang, W., et al. (2020). A pneumonia outbreak associated with a new coronavirus of probable bat origin. Nature, 579(7798), 270273. https://doi.org/10.1038/s41586-020-2012-7

8. Tortorici, M. A., \& Veesler, D. (2019). Structural insights into coronavirus entry. Advances in Virus Research, 105, 93-116. https://doi.org/10.1016/bs.aivir.2019.08.002

9. Zhang, H., Penninger, J. M., Li, Y., Zhong, N., \& Slutsky, A. S. (2020). Angiotensin-converting enzyme 2 (ACE2) as a SARS$\mathrm{CoV}-2$ receptor: Molecular mechanisms and potential therapeutic target. Intensive Care Medicine, 46(4), 586-590. https://doi. org/10.1007/s00134-020-05985-9

10. Walls, A. C., Park, Y. J., Tortorici, M. A., Wall, A., McGuire, A. T., \& Veesler, D. (2020). Structure, function, and antigenicity of the SARS-CoV-2 spike glycoprotein. Cell, 181(2), 281-292. e6. https://doi.org/10.1016/j.cell.2020.02.058

11. Walls, A. C., Xiong, X., Park, Y. J., Tortorici, M. A., Snijder, J., Quispe, J., et al. (2019). Unexpected receptor functional mimicry elucidates activation of coronavirus fusion. Cell, 176(5), 1026-1039.e15. https://doi.org/10.1016/j.cell.2018.12.028

12. Li, T., Zheng, Q., Yu, H., Wu, D., Xue, W., Zhang, Y., et al. (2020). Characterization of the SARS-CoV-2 spike in an early prefusion conformation. bioRxiv. https://doi.org/10.1101/2020. 03.16 .994152

13. Henderson, R., Edwards, R., Mansouri, K., Janowska, K., Stalls, V., Kopp, M., et al. (2020). Glycans on the SARS-CoV-2 spike control the receptor binding domain conformation. bioRxiv. https://doi.org/10.1101/2020.06.26.173765

14. Tian, X., Li, C., Huang, A., Xia, S., Lu, S., Shi, Z., et al. (2020). Potent binding of 2019 novel coronavirus spike protein by a SARS coronavirus-specific human monoclonal antibody. Emerging Microbes and Infections, 9(1), 382-385. https://doi. org/10.1080/22221751.2020.1729069

15. van den Brink, E. N., ter Meulen, J., Cox, F., Jongeneelen, M. A. C., Thijsse, A., Throsby, M., et al. (2005). Molecular and biological characterization of human monoclonal antibodies binding to the spike and nucleocapsid proteins of severe acute respiratory syndrome coronavirus. Journal of Virology, 79(3), 1635-1644. https://doi.org/10.1128/jvi.79.3.1635-1644.2005

16. ter Meulen, J., van den Brink, E. N., Poon, L. L. M., Marissen, W. E., Leung, C. S. W., Cox, F., et al. (2006). Human monoclonal antibody combination against SARS coronavirus: Synergy and coverage of escape mutants. PLoS Medicine, 3(7), e237. https://doi.org/10.1371/journal.pmed.0030237

17. Yuan, M., Wu, N. C., Zhu, X., Lee, C. C. D., So, R. T. Y., Lv, H., et al. (2020). A highly conserved cryptic epitope in the receptor binding domains of SARS-CoV-2 and SARS-CoV. Science, 368(6491), 630-633. https://doi.org/10.1126/science. abb7269

18. Huo, J., Zhao, Y., Ren, J., Zhou, D., Duyvesteyn, H. M. E., Ginn, H. M., et al. (2020). Neutralization of SARS-CoV-2 by destruction of the prefusion spike. Cell Host and Microbe, 28(3), 445-454.e6. https://doi.org/10.1016/j.chom.2020.06.010 
19. Wu, N. C., Yuan, M., Bangaru, S., Huang, D., Zhu, X., Lee, C.C.D., et al. (2020). A natural mutation between SARS-CoV-2 and SARS-CoV determines neutralization by a cross-reactive antibody. PLOS Pathogens, 16(12), e1009089. https://doi.org/ 10.1371/journal.ppat.1009089

20. Shi, R., Shan, C., Duan, X., Chen, Z., Liu, P., Song, J., et al. (2020). A human neutralizing antibody targets the receptorbinding site of SARS-CoV-2. Nature, 584(7819), 120-124. https://doi.org/10.1038/s41586-020-2381-y

21. Wu, Y., Wang, F., Shen, C., Peng, W., Li, D., Zhao, C., et al. (2020). A noncompeting pair of human neutralizing antibodies block COVID-19 virus binding to its receptor ACE2. Science, 368(6496), 1274-1278. https://doi.org/10.1126/science.abc22 41

22. Ahmad, Z. A., Yeap, S. K., Ali, A. M., Ho, W. Y., Alitheen, N. B. M., \& Hamid, M. (2012). ScFv antibody: Principles and clinical application. Clinical and Developmental Immunology, 2012, 980250. https://doi.org/10.1155/2012/980250

23. Bera, T. K., Onda, M., Kreitman, R. J., \& Pastan, I. (2014). An improved recombinant Fab-immunotoxin targeting CD22 expressing malignancies. Leukemia Research, 38(10), 1224-1229. https:// doi.org/10.1016/j.leukres.2014.06.014

24. Jefferis, R. (2008). Glycosylation of recombinant antibody therapeutics. Biotechnology Progress, 21(1), 11-16. https://doi.org/10. 1021/bp040016j

25. Wurm, F. M. (2004). Production of recombinant protein therapeutics in cultivated mammalian cells. Nature Biotechnology, 22(11), 1393-1398. https://doi.org/10.1038/nbt1026

26. Jäger, V., Büssow, K., Wagner, A., Weber, S., Hust, M., Frenzel, A., \& Schirrmann, T. (2013). High level transient production of recombinant antibodies and antibody fusion proteins in HEK293 cells. BMC Biotechnology, 13(1), 1-20. https://doi.org/10.1186/ 1472-6750-13-52

27. Morifuji, Y., Xu, J., Karasaki, N., Iiyama, K., Morokuma, D., Hino, M., et al. (2018). Expression, purification, and characterization of recombinant human $\alpha 1$-antitrypsin produced using silkworm-baculovirus expression system. Molecular Biotechnology, 60(12), 924-934. https://doi.org/10.1007/s12033-018-0127-y

28. Kakino, K., Masuda, A., Hino, M., Ebihara, T., Xu, J., Mon, H., et al. (2020). Efficient production of recombinant T7 endonuclease I using silkworm-baculovirus expression vector system. Journal of Asia-Pacific Entomology, 23(3), 694-700. https://doi.org/10. 1016/j.aspen.2020.05.001

29. Fujita, R., Hino, M., Ebihara, T., Nagasato, T., Masuda, A., Lee, J. M., et al. (2020). Efficient production of recombinant SARSCoV-2 spike protein using the baculovirus-silkworm system. Biochemical and Biophysical Research Communications, 529(2), 257-262. https://doi.org/10.1016/j.bbrc.2020.06.020

30. Shiroishi, M., Ito, Y., Shimokawa, K., Lee, J. M., Kusakabe, T., \& Ueda, T. (2018). Structure-function analyses of a stereotypic rheumatoid factor unravel the structural basis for germlineencoded antibody autoreactivity. Journal of Biological Chemistry, 293(18), 7008-7016. https://doi.org/10.1074/jbc.M117.814475

31. Gibson, D. G., Young, L., Chuang, R. Y., Venter, J. C., Hutchison, C. A., \& Smith, H. O. (2009). Enzymatic assembly of DNA molecules up to several hundred kilobases. Nature Methods, 6(5), 343-345. https://doi.org/10.1038/nmeth.1318

32. Ono, C., Nakatsukasa, T., Nishijima, Y., Asano, S. I., Sahara, K., $\&$ Bando, H. (2007). Construction of the BmNPVT3 bacmid system and its application to the functional analysis of BmNPV he65. Journal of Insect Biotechnology and Sericology, 76(3), 161-167. https://doi.org/10.11416/jibs.76.3_161

33. Wrapp, D., Wang, N., Corbett, K. S., Goldsmith, J. A., Hsieh, C. L., Abiona, O., et al. (2020). Cryo-EM structure of the 2019nCoV spike in the prefusion conformation. Science, 367(6483), 1260-1263. https://doi.org/10.1126/science.abb2507
34. Grifoni, A., Sidney, J., Zhang, Y., Scheuermann, R. H., Peters, B., \& Sette, A. (2020). A sequence homology and bioinformatic approach can predict candidate targets for immune responses to SARS-CoV-2. Cell Host and Microbe, 27(4), 671-680.e2. https:// doi.org/10.1016/j.chom.2020.03.002

35. Stöger, E., Vaquero, C., Torres, E., Sack, M., Nicholson, L., Drossard, J., et al. (2000). Cereal crops as viable production and storage systems for pharmaceutical scFv antibodies. Plant Molecular Biology, 42(4), 583-590. https://doi.org/10.1023/A:1006301519 427

36. Damasceno, L. M., Pla, I., Chang, H. J., Cohen, L., Ritter, G., Old, L. J., \& Batt, C. A. (2004). An optimized fermentation process for high-level production of a single-chain Fv antibody fragment in Pichia pastoris. Protein Expression and Purification, 37(1), 18-26. https://doi.org/10.1016/j.pep.2004.03.019

37. Kurasawa, J. H., Shestopal, S. A., Jha, N. K., Ovanesov, M. V., Lee, T. K., \& Sarafanov, A. G. (2013). Insect cell-based expression and characterization of a single-chain variable antibody fragment directed against blood coagulation factor VIII. Protein Expression and Purification, 88(2), 201-206. https://doi.org/10. 1016/j.pep.2012.12.008

38. Miller, K. D., Weaver-Feldhaus, J., Gray, S. A., Siegel, R. W., \& Feldhaus, M. J. (2005). Production, purification, and characterization of human $\mathrm{scFv}$ antibodies expressed in Saccharomyces cerevisiae, Pichia pastoris, and Escherichia coli. Protein Expression and Purification, 42(2), 255-267. https://doi.org/10.1016/j.pep. 2005.04.015

39. Sarker, A., Rathore, A. S., \& Gupta, R. D. (2019). Evaluation of $\mathrm{scFv}$ protein recovery from $E$. coli by in vitro refolding and mild solubilization process. Microbial Cell Factories, 18(1), 5. https:// doi.org/10.1186/s12934-019-1053-9

40. Rattanapisit, K., Shanmugaraj, B., Manopwisedjaroen, S., Purwono, P. B., Siriwattananon, K., Khorattanakulchai, N., et al. (2020). Rapid production of SARS-CoV-2 receptor binding domain (RBD) and spike specific monoclonal antibody CR3022 in Nicotiana benthamiana. Scientific Reports. https://doi.org/10. 1038/s41598-020-74904-1

41. Lu, D., Jimenez, X., Witte, L., \& Zhu, Z. (2004). The effect of variable domain orientation and arrangement on the antigen-binding activity of a recombinant human bispecific diabody. Biochemical and Biophysical Research Communications, 318(2), 507-513. https://doi.org/10.1016/j.bbrc.2004.04.060

42. Riaño-Umbarila, L., Rojas-Trejo, V. M., Romero-Moreno, J. A., Costas, M., Utrera-Espíndola, I., Olamendi-Portugal, T., et al. (2020). Comparative assessment of the VH-VL and VL-VH orientations of single-chain variable fragments of scorpion toxinneutralizing antibodies. Molecular Immunology, 122, 141-147. https://doi.org/10.1016/j.molimm.2020.04.015

43. Yan, Y., Chang, L., \& Wang, L. (2020). Laboratory testing of SARS-CoV, MERS-CoV, and SARS-CoV-2 (2019-nCoV): Current status, challenges, and countermeasures. Reviews in Medical Virology, 30(3), e2106. https://doi.org/10.1002/rmv.2106

44. Milligan, C., Richardson, B. A., John-Stewart, G., Nduati, R., \& Overbaugh, J. (2015). Passively acquired antibody-dependent cellular cytotoxicity (ADCC) activity in HIV-infected infants is associated with reduced mortality. Cell Host and Microbe, 17(4), 500-506. https://doi.org/10.1016/j.chom.2015.03.002

45. Jegaskanda, S., Luke, C., Hickman, H. D., Sangster, M. Y., Wieland-Alter, W. F., McBride, J. M., et al. (2016). Generation and protective ability of influenza virus-specific antibody-dependent cellular cytotoxicity in humans elicited by vaccination, natural infection, and experimental challenge. Journal of Infectious Diseases, 214(6), 945-952. https://doi.org/10.1093/infdis/jiw262

46. Carter, P. (2001). Improving the efficacy of antibody-based cancer therapies. Nature Reviews Cancer, 1(2), 118-129. https://doi.org/ $10.1038 / 35101072$ 
47. Iida, S., Misaka, H., Inoue, M., Shibata, M., Nakano, R., YamaneOhnuki, N., et al. (2006). Nonfucosylated therapeutic IgG1 antibody can evade the inhibitory effect of serum immunoglobulin $\mathrm{G}$ on antibody-dependent cellular cytotoxicity through its high binding to FcyRIIIa. Clinical Cancer Research, 12(9), 2879-2887. https://doi.org/10.1158/1078-0432.CCR-05-2619

48. Iida, S., Kuni-Kamochi, R., Mori, K., Misaka, H., Inoue, M., Okazaki, A., et al. (2009). Two mechanisms of the enhanced antibody-dependent cellular cytotoxicity (ADCC) efficacy of nonfucosylated therapeutic antibodies in human blood. BMC Cancer, 9(1), 58. https://doi.org/10.1186/1471-2407-9-58
49. Tada, M., Tatematsu, K., Ishii-Watabe, A., Harazono, A., Takakura, D., Hashii, N., et al. (2015). Characterization of antiCD20 monoclonal antibody produced by transgenic silkworms (Bombyx mori). MAbs, 7(6), 1138-1150. https://doi.org/10.1080/ 19420862.2015.1078054

Publisher's Note Springer Nature remains neutral with regard to jurisdictional claims in published maps and institutional affiliations. 